\title{
Relationship between frailty and respiratory function in the community-dwelling elderly
}

\author{
Maycon S. Pegorari, Gualberto Ruas, Lislei J. Patrizzi
}

ABSTRACT | Objective: To evaluate the impact of frailty on respiratory function in a community- dwelling elderly. Method: 51 community-dwelling elderly were evaluated (mean age of $73 \pm 6$ years), being 29 men (56.7\%) and 22 women $(43.3 \%)$. We collect the following variables: sociodemographic characteristics, frailty phenotype, pulmonary function test and assessment of the respiratory muscles using an analog manometer. The statistical analysis was performed using the Kolmogorov and Smirnov tests, one-way ANOVA, Paired Student's t-test and Pearson correlation coefficient $(\mathrm{p}<0.05)$. Results: There were no statistically significant between-group differences among the frail group ( $\mathrm{FG}=9.8 \%$ ), pre-frail group $(\mathrm{PG}=47.1 \%)$ and non-frail group $(\mathrm{NG}=43.1 \%)$, in relation to anthropometric, demographic and spirometric data. Regarding to the maximum inspiratory and expiratory pressures (MIP and MEP), statistically significant between-group differences were observed among the three groups, being these pressures significantly lower in the FG and PG compared to the NG. With regards to the obtained and predicted values, the FG and PG showed statistically significant difference $(\mathrm{p}=0.004)$. The PG showed positive correlations between the MIP and MEP with the values of hand grip strength $(\mathrm{r}=0.7)$. The NG showed positive correlation between the MEP and the values of physical activity level $(r=0.7)$. Conclusions: The study demonstrated that maximal respiratory pressures may decrease according to the frailty condition among the nonfrail, pre-frail and frail elderly. Furthermore, it also indicated a positive correlation between inspiratory muscle strength, expiratory muscle strength and hand grip strength in pre-frail elderly. Further investigation with regards to prevention or intervention programs that incorporate actions to minimize the loss of respiratory function are necessary in order to reverse or prevent the progression of the frailty condition.

Keywords: frail elderly; respiratory function tests; spirometry; physical therapy.

HOW TO CITE THIS ARTICLE

Pegorari MS, Ruas G, Patrizzi LJ. Relationship between frailty and respiratory function in the community-dwelling elderly. Braz J Phys Ther. 2013 Jan-Feb; 17(1):9-16. http://dx.doi.org/10.1590/S1413-35552012005000065

\section{Introduction}

The frailty syndrome can be defined as the decrease in both energy reserves and resistance to stressors. It results from cumulative declines across multiple physiological systems and causes vulnerability to adverse health conditions. The decrease in function across some systems is related to the aging process, such as neuroendocrine dysregulation, immune dysfunction and neuromuscular disorders. This condition increases vulnerability to adverse health outcomes, such as morbidity, dependency, falls, hospitalization and mortality ${ }^{1-3}$.

Fried et al. ${ }^{1}$ proposed a construction of a phenotype related to frailty, composed by five items that could be measured: unintentional weight loss, selfreported fatigue, decreased hand grip strength, low physical activity level and slow walking speed. Therefore, the main components of this syndrome are: chronic malnutrition, sarcopenia, decreased muscle strength, declining exercise tolerance, decreased levels of physical activity, decreased energy expenditure and imobility ${ }^{4,5}$. Another study has established a strong association between frailty and respiratory dysfunction evaluated by spirometry in the community-dwelling elderly and the presence of both characteristics may increase substantially the risk of death ${ }^{6}$.

Changes in respiratory mechanics are more evident by the reduction in the physiological capacity during the aging process, which also include a progressive increase in chest wall stiffness and a decrease of the elastic lung component. These changes, associated with respiratory infections and frequent exposure to stressors, such as toxic particles from the environment and smoking, can lead to airflow limitation, which 
is defined by a decrease in the ratio between forced expiratory volume $\left(\mathrm{FEV}_{1}\right)$ and forced vital capacity (FVC), and may be accompanied by an increase in residual volume and functional residual capacity ${ }^{7-9}$.

The aging process promotes the decrease in muscle mass, strength and function, with repercussion in the respiratory muscles ${ }^{10-12}$. This situation may impact the performance of daily living activities, as well as in the functional capacity ${ }^{13}$. Studies have reported a negative correlation between age and respiratory muscle strength in the elderly ${ }^{14-17}$, however, it can be observed that these studies did not considered the frailty syndrome in their investigations.

Weiss et al. ${ }^{18}$ and Vaz Fragoso et al. ${ }^{6}$ emphasized in their studies the need to use other measurements to investigate pulmonary function in frail elderly, such as the evaluation of maximal respiratory pressures. Therefore, the aim of this study was to evaluate the impact of frailty on respiratory function in community-dwelling elderly.

\section{Method}

\section{Study design and ethical aspects}

This is quantitative, observational, descriptive and analytical cross-sectional study. The study was approved by the Ethics Committee in Research of the Universidade Federal do Triangulo Mineiro (UFTM), Brazil (n 1815/11).

\section{Participants}

The study was conducted with elderly participants registered in the Family Health Unit (FHU). Therefore, we examined all the records from the selected FHT, where there were 549 registered elderly that were monitored.

The participants were randomly selected through opaque envelopes. To be included, they should be older than 65 years old, being of both genders, agree to participate, be permanent residents at residence from the enrolled area of the FHT, be able to walk, being allowed the use of device for gait assistance (cane, crutch or walker). The elderly with cognitive impairment assessed through the Mini Mental State Examination (MMSE) ${ }^{19}$ and neurological diseases that compromised their performance in the assessments were excluded.

From the 549 elderly enrolled at the FHU, 390 elderly met the inclusion criteria and were selected to be possibly included in this study. The sample size was calculate using the maximum percentage to the prevalence of frailty $(6.9 \%)$ according to Fried et al. ${ }^{1}$ study and with a confidence level of $90 \%$, being a sample of 73 elderly.

After the randomization, 86 elderly were invited via phone or via visit in their homes to attend the FHU. From these, 11 elderly refused to participate in the study, 2 died, 9 had no physical conditions to attend the FHU, 5 changed their address, 6 did not meet the cutoff point on the MMSE, 1 refused to continue the assessments and 1 was unable to perform the tests for the lung function evaluation (spirometry and manovacuometry), totaling 35 elderly excluded. Finally, the sample consisted of 51 communitydwelling elderly ( 31 women and 20 men), considering a significance level of 5\% and a power of $80 \%$.

\section{Procedures}

Cognitive impairment was evaluated by the MMSE $^{19}$. All participants with no cognitive impairment were invited to participate and were informed about the nature and aim of the study. After accepting to participate in the study, they signed an informed consent form. Data collection was performed in two stages collected in different days: the first stage aimed to evaluate the cognitive level and to record the sociodemographic, anthropometric and indicators of frailty data; and the second stage aimed to evaluate the of respiratory variables, such as respiratory muscle strength and lung volumes. Participants were evaluated by the same examiner, which was properly qualified and trained to perform the assessments.

\section{Instruments and measures}

To evaluate the sociodemographic characteristics, the following variables were collected: gender, age, skin color/race, education, marital status, occupational status and living arrangement.

Anthropometric data and body mass index (BMI) were measured using a calibrated anthropometric scale $\left(\right.$ Filizola $^{\circledR}$ ), with subject wearing as little clothing as possible. Body mass was obtained in kilograms (kg) and height in meters (m). BMI was calculated by dividing body weight by the square of height $\left(\mathrm{kg} / \mathrm{m}^{2}\right)$.

The presence of frailty syndrome was verified by testing for identification of the five items described as components of the phenotype of frailty proposed by 
Fried et al. ${ }^{1}$, as follows: 1) Unintentional weight loss: was evaluated by the following question, "In last year, did you lost more than $4.5 \mathrm{~kg}$ unintentionally (i.e. without diet or exercise)?" It was given positive score for the frailty criterion when the self-reported weight loss was greater than $4.5 \mathrm{~kg}$ in the last year or more than 5\% of body weight; 2) Muscle Strength: was verified based on hand grip strength using a manual hydraulic dynamometer, model NC701/42 - North Coast $^{\mathrm{TM}}$. The cutoff points proposed by Silva et al. ${ }^{20}$ were adopted, adjusted for gender and BMI; 3) Selfreported exhaustion: was evaluated by two questions from the Brazilian version of the depression scale of the Center for Epidemiological Studies (CES-D) ${ }^{21}$; 4) Low walking speed: was evaluated by time spent to walk a distance of $4.6 \mathrm{~m}$. The cutoffs points proposed by Silva et al. ${ }^{20}$ adjusted for gender and height were used; 5) Low physical activity level: was measured by weekly energy expenditure in kilocalories (Kcal). It was evaluated using the self-reported performance questionnaire Profile of Human Activity (PHA) ${ }^{22}$. To calculate the cutoff points, the $20^{\text {th }}$ percentile of the assumed values of the variables collected in the sample was determined, according to gender. Low physical activity level was scored if the weekly energy expenditure was lower than $163.23 \mathrm{kcal}$ for elderly men and lower than $173.17 \mathrm{kcal}$ for elderly women. Elderly who have scored positive three or more of the items mentioned above were classified as frail, and those who have scored positive one or two items were classified as pre-frail. Elderly who have scored negative for all tested items for the frailty syndrome were considered strong or non-frail ${ }^{1}$.

To evaluate the lung volumes, the spirometer EasyOne ${ }^{\mathrm{TM}}$ was used according the Guidelines of the Brazilian Society of Pulmonology and Tisiology ${ }^{23}$. The spirometer was property calibrated. The

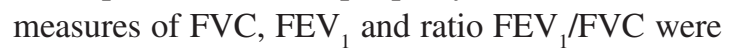
obtained with two-minute intervals and at least three maneuvers. The measures were collected with the participants in the sitting position, feet resting on the floor, spine erect, without support for the upper limbs and using a nose clip. Spirometric values were expressed as the percentage of the normal predicted value for the Brazilian population ${ }^{24}$.

The respiratory muscle strength was measured using an analog manometer $\left(\right.$ Ger-Air ${ }^{\circledR}$, São Paulo, Brazil), with scales ranging from -300 to $+300 \mathrm{cmH}_{2} \mathrm{O}$ (properly calibrated). The analog manometer was equipped with a plastic trachea of 16 $\mathrm{cm}$ long and $2.4 \mathrm{~cm}$ of internal diameter, hard plastic mouthpiece and escape orifice of approximately $2 \mathrm{~mm}$ diameter for dissipation of pressures generated by the muscles of the face and oropharyn $\mathrm{x}^{25}$. The measures of maximal inspiratory pressure (MIP) and maximal expiratory pressure (MEP) were obtained, being performed a maximal of five acceptable and reproducible measurements. These measures were performed with the participants in the sitting position, using a nose clip, with a sustained period of three seconds. The MIP value was obtained from the residual volume, and the MEP values was obtained from the total lung capacity. The elderly received proper verbal encouragement and, if a difference greater than $10 \%$ difference between one measure and another were observed a new maneuver was performed, considering the highest value obtained since this maneuver was not the last one ${ }^{26}$.

\section{Statistical analysis}

Data were analyzed using the statistical program InStat, version 3.05 (GraphPad Software Inc, San Diego, CA, USA). The mean and standard deviations were calculated. In the between-group analysis, the Kolmogorov-Smirnov test was performed to evaluate the data distribution. As the variables were normally distributed one-way ANOVA was used. For the analyzed variables with a statistical significant difference between-group, the post hoc Duncan test was applied for ordering these variables.

To compare the obtained and predicted values of respiratory pressures, paired Student's t test was used. Pearson correlation coefficient was used for test the correlations between the variables. The level of significance was set at $5 \%$.

\section{Results}

The sample included 51 elderly non-smokers, 29 men (56.7\%) and 22 women (43.3\%) with mean age of $73 \pm 6$ years, mean height of $1.56 \pm 0.8 \mathrm{~m}$, mean weight of $65 \pm 11 \mathrm{~kg}$ and BMI of $26 \pm 4 \mathrm{~kg} / \mathrm{m}^{2}$. In addition, 37 (72\%) elderly were white, nine (17\%) were mulatto/cabocla/brown and five $(9.8 \%)$ were from black race. Most were married $(56.9 \%, \mathrm{n}=29)$ and $35.3 \%(\mathrm{n}=18)$ were widowed. The educational level of $74.5 \%$ of the elderly $(n=38)$ was primary, while $5.9 \%(n=3)$ of the elderly had a lower level of education. In relation to work, $84.3 \%(n=43)$ of the elderly reported that they were not working at the moment, and the vast majority, comprised by 44 elderly (84.3\%) was retired. The average number 
of children per elderly was $4.8 \pm 3.87$ and $41(80.4 \%)$ of the elderly reported that they did not live alone. The mean MMSE score was $25 \pm 3$.

To perform the analyses the sample was divided into three groups: frail (FG), pre-frail (PG) and nonfrail (NG). Using the operational definition described by Fried et al. ${ }^{1}$, the prevalence was: five $(9.8 \%)$ elderly were classified as frail (FG), 24 (47.1\%) were classified in the intermediate phase of frailty, pre-fail (PG), and $22(43.1 \%)$ as non-frail (NG).

Sixteen $(31.4 \%)$ elderly scored positive in the unintentional weight loss criterion, six $(11.76 \%)$ scored positive for exhaustion criterion, four $(7.8 \%)$ presented decreased hand grip strength, 12 (23.5\%) scored positive in the reduced gait speed criterion and ten (19.6\%) scored positive for reduced physical activity level criterion.

The anthropometric, demographic and spirometric characteristics and also the inspiratory and expiratory pressures of the FG, PG and NG are shown in Table 1.

There were no statistically significant differences between the FG, $\mathrm{PG}$ and $\mathrm{NG}$ in relation to anthropometric, demographic and spirometric data, but the maximum inspiratory and expiratory pressures showed statically significant differences among the three groups ( $\mathrm{p}=0.006$; one-way ANOVA test).

The FG presented MIP and MEP values significantly lower in relation to PG and NG, while the PG presented lower values when compared with
NG ( $\mathrm{p}=0.004$; Duncan post hoc). With regards to the obtained MIP and MEP values versus predicted values, the FG and PG showed statistically significant differences ( $\mathrm{p}=0.004$; Paired Student's t test) (Table 1).

Table 2 presents the correlation analyses. As can be observed the MIP and MEP were positive correlated with the values of hand grip strength for the PG $(r=0.7 ; p=0.0007$ and $r=0.7 ; p=0.0006$ respectively). On the other hand, positive correlation between MEP and the values of physical activity level $(r=0.7$; $\mathrm{p}=0.002$ ) was observed in the PG.

\section{Discussion}

Studies evaluating the relationship between frailty syndrome and respiratory function in the elderly are scarce, and changes in lung function due to the aging process are relevant, since a poor pulmonary condition is associated with high rates of mortality ${ }^{27}$.

Vaz Fragoso et al. ${ }^{6}$ demonstrated cross-sectional and longitudinal associations between frailty and respiratory dysfunction in a sample of 3.578 white elderly, aged between 65 and 80 years. In the cross-sectional analysis, pre-frail and frail elderly presented $62 \%$ and $88 \%$ of probability of having airflow limitation and $80 \%$ and $205 \%$ of a restrictive lung function pattern, respectively. In the longitudinal analysis, elderly with underlying

Table 1. Anthropometric and clinical characteristics between groups.

\begin{tabular}{|c|c|c|c|}
\hline Variables & FG & PG & NG \\
\hline $\mathbf{N}(\%)$ & $5(9.8)$ & $24(47.1)$ & $22(43.1)$ \\
\hline Age (years) & $70 \pm 3$ & $75 \pm 7$ & $71 \pm 5$ \\
\hline Weight (Kg) & $67 \pm 13$ & $63 \pm 13$ & $66 \pm 8$ \\
\hline Height (cm) & $152 \pm 8$ & $154 \pm 8$ & $160 \pm 8$ \\
\hline BMI $\left(\mathrm{Kg} / \mathbf{m}^{2}\right)$ & $29 \pm 5$ & $27 \pm 7$ & $25 \pm 3$ \\
\hline FVC (\% pred) & $77 \pm 4$ & $80 \pm 3$ & $81 \pm 9$ \\
\hline $\mathrm{FEV}_{1}(\%$ pred $)$ & $78 \pm 7$ & $79 \pm 2$ & $82 \pm 14$ \\
\hline $\mathrm{FEV}_{1} / \mathrm{FVC}(\%)$ & $101 \pm 13$ & $95 \pm 14$ & $100 \pm 5$ \\
\hline $\mathrm{MIP}\left(\mathrm{cmH}_{2} \mathrm{O}\right)$ & $50 \pm 10 \dagger \S$ & $58 \pm 18 \dagger \dagger £$ & $72 \pm 25 *$ \\
\hline MIP $\left(\mathrm{cmH}_{2} \mathrm{O}\right)$ predicted & $80 \pm 8 \S$ & $79 \pm 9 £$ & $86 \pm 11$ \\
\hline $\mathrm{MIP}\left(\mathrm{cmH}_{2} \mathrm{O}\right)(\%$ pred $)$ & $62 \pm 15$ & $72 \pm 19$ & $83 \pm 24$ \\
\hline $\operatorname{MEP}\left(\mathrm{cmH}_{2} \mathrm{O}\right)$ & $48 \pm 10 \dagger \S$ & $61 \pm 18+\uparrow £$ & $83 \pm 29 *$ \\
\hline MEP $\left(\mathrm{cmH}_{2} \mathrm{O}\right)$ predicted & $79 \pm 14 \S$ & $79 \pm 14 £$ & $91 \pm 18$ \\
\hline $\operatorname{MEP}\left(\mathrm{cmH}_{2} \mathrm{O}\right)(\%$ pred $)$ & $60 \pm 13$ & $76 \pm 13$ & $90 \pm 23$ \\
\hline
\end{tabular}

FG: frail group, PG: pre-frail group, NG: non-frail group. Data are express as percentage (\%), mean \pm standard deviation; $\mathrm{kg}$ : kilograms, $\mathrm{cm}$ : centimeter, $\mathrm{Kg} / \mathrm{m}^{2}$ :per square meter, FVC: forced vital capacity, FEV1: forced expiratory volume in one second; FEV $/ \mathrm{FVC}$ : ratio of forced expiratory volume in one second and forced vital capacity; \%pred: percentage of predicted; $\uparrow: \mathrm{FG}<\mathrm{PG}<\mathrm{NG} ; \dagger$ : $\mathrm{PG}<\mathrm{NG}, \S$ and $£$ : significant between measured and predicted values; * significant between groups $(\mathrm{p}<0,05)$. 
Table 2. Correlation between MIP, MEP and indicators of fragility (HS, WS e PAL).

$\begin{array}{clll}\text { Variables } & \text { FG } & \text { PG } & \text { NG } \\ \text { MIP vs HS } & \mathrm{r}=-0.004^{(\mathrm{NS})} & \mathbf{r}=\mathbf{0 . 7 ^ { * }} & \mathrm{r}=-0.5^{(\mathrm{NS})} \\ \text { MIP vs WS } & \mathrm{r}=-0.1^{(\mathrm{NS})} & \mathrm{r}=-0.3^{(\mathrm{NS})} & \mathrm{r}=-0.2^{(\mathrm{NS})} \\ \text { MIP vs PAL } & \mathrm{r}=-0.8^{(\mathrm{NS})} & \mathrm{r}=0.3^{(\mathrm{NS})} & \mathrm{r}=0.5^{(\mathrm{NS})} \\ \text { MEP vs HS } & \mathrm{r}=0.4^{(\mathrm{NS})} & \mathbf{r}=\mathbf{0 .} & \mathrm{r}=-0.5^{(\mathrm{NS})} \\ \text { MEP vs WS } & \mathrm{r}=0.3^{(\mathrm{NS})} & \mathrm{r}=-0.4^{(\mathrm{NS})} & \mathrm{r}=-0.2^{(\mathrm{NS})} \\ \text { MEP vs PAL } & \mathrm{r}=-0.2^{\mathrm{NS})} & \mathrm{r}=-0.1^{\mathrm{NS})} & \mathbf{r}=\mathbf{0 . 7 ^ { * }}\end{array}$

FG: frail group, PG: pre-frail group, NG: non-frail group; MIP: maximum inspiratory pressure; MEP: maximal expiratory pressure; HS: handgrip strength; WS: walk speed; PAL: physical activity level; vs: versus; r: Pearson correlation; *: significant ( $<0$, 05); (NS): not significant.

frailty characteristics were more likely to develop respiratory dysfunction. On the other hand, elderly with underlying respiratory dysfunction were more likely to develop frailty.

This study found that there was no statistically significant difference between the FG, PG and NG in relation to anthropometric and demographic data. Compromise of the spirometric variables was not observed in this study, being the results within the normative values ${ }^{24}$. Future studies with larger samples are needed, since the frailty syndrome and respiratory dysfunction seem to have a strong association with increased risk of death ${ }^{6}$.

During the aging process there is a decline in FVC and $\mathrm{FEV}_{1}$ with an increase in functional residual capacity (FRC) due to the higher closing volume and an increase in residual volume (RV). These may happen because when the lung volume is lower, there is a tendency of small airways to collapse, and these changes account for the higher lung static compliance ${ }^{14,28,29}$. The authors also highlight a reduction in respiratory muscle strength, in lung elastic recoil and in thoracic compliance ${ }^{28,30,31}$, as well as a reduction in respiratory response to hypoxemia and hypercapnia, lower perception of increased resistance of airway ${ }^{14}$, and physiological changes associated with aging that affect the lung function in the elderly ${ }^{14,17,28,30,32-34}$.

The disappearance of synovial joints between the sternum and the costal cartilages decreases the chest-wall compliance and tension forces, with consequent decrease in maximal respiratory pressure and hypotrophy of accessory respiratory muscles ${ }^{7-9}$.

The key results presented in this study were related with the behavior of the variables MIP and MEP in the FG, PG and NG. To our knowledge there is no study that has mentioned the relationship between frailty syndrome and maximal respiratory pressures, especially in the Brazilian population.
However, evidence suggests that muscle changes associated with aging compromise the function of the respiratory muscles, with a significant decrease around $25 \%$ on the diaphragm strength of the elderly, when compared with young adults ${ }^{35}$. Furthermore, it is suggested that the changes induced by the frailty condition may explain the findings between groups, since the components of this syndrome accelerate the sarcopenia process ${ }^{1,4,5}$, intensifying the negative impact on respiratory muscle strength.

Regarding the behavior of respiratory pressures, the FG showed lower values $(p<0.05)$ for MIP and MEP when compared with the PG and NG, suggesting reduced respiratory muscle strength. This reduction may generate reductions in tidal volume, with increase in the frequency and respiratory effort ${ }^{7}, 30,36,37$.

Other conditions may support such situation, such as lung hyperinflation, which occurs decrease of the resting length of the diaphragm muscle and reduction of chest-wall movements, resulting in reduced strength, lower transdiaphragmatic pressure and lower MIP T,30,36,37. $^{2}$.

$\mathrm{Kim}^{38}$ highlighted that the inspiratory muscles are considered the most relevant in relation to function, fatigue and training. However, expiratory muscles may promote inspiration, preventing the shortening and increasing the diaphragm strength ${ }^{39}$.

During strenuous exercise, there is a contraction of the expiratory muscles, with decrease in the residual volume, which contributes to the diaphragm acting in a more convenient length. Increase in the ventilation through the abdominal musculature can prolong or prevent the onset of inspiratory muscle fatigue. The recruitment of this musculature and the consequent decrease in residual volume occur during exercises with resistance to inspiratory flow ${ }^{39}$.

The commitment of the expiratory muscles leads to decrease flow and damage to the cough mechanism ${ }^{40}$, 
predisposing the secretions accumulation and the development of bronchopulmonary infections ${ }^{41}$.

Factors such as nutritional status, hand grip strength and physical activity level can compromise the respiratory function ${ }^{42}$.

Changes in nutritional status predict changes in the respiratory system, including changes in the structure of the respiratory muscle ${ }^{42}$, with muscles more susceptible to fatigue and failure, as well as depression of the immune system and increased risk of infections ${ }^{33}$. In this study was observed that $31.4 \%$ of the sample reported unintentional weight loss, and it may have contributed with the findings of this study. Therefore, respiratory muscle strength and unintentional weight loss should be objects of future investigation.

It was observed in this study that the values of MIP and MEP correlated significantly with the hand grip strength in the PG. Studies ${ }^{43-45}$ indicate that the overall muscle strength can be estimated by the hand grip strength, being used as an important predictor of adverse clinical outcomes, such as functional disability, hospitalization, and mortality. Otherwise, frailty is associated with muscle strength loss and sarcopenia, which seems to be the main reason for changes in activity pattern and decreased musculoskeletal function, with consequent increase of the frailty condition in the ederly ${ }^{46-48}$.

Accordingly, changes in the skeletal muscles due to aging can compromise respiratory muscle function ${ }^{10-12}$. Therefore, the results obtained in this study suggest that elderly under pre-frailty condition may present lower hand grip strength associated with reduced respiratory muscle strength. This relationship was not observed in FG, probably due to the small number of elderly in this group.

In the study conducted by Vaz Fragoso et al. ${ }^{6}$, it was found that reduced gait speed (RGS) and low physical activity level were associated with airflow limitation in a cross-sectional analysis, while RGS, low physical activity level and reduced hand grip strength were associate with the restrictive lung function pattern.

Pulmonary rehabilitation programs may be established as an adequate strategy to the needs of frail elderly with respiratory disfunction ${ }^{6}$. Thus, the optimization of maximal respiratory pressures through respiratory muscle training is an additional physical therapy resource ${ }^{13}$, necessary in prevention or intervention programs for the elderly population in frailty condition.
The results found in this study, regarding the correlation between MIP and MEP and gait speed and physical activity level, should be interpreted with caution, especially in the FG. Limitations include cross-sectional nature that precludes inferring causality; the instrument used to measure hand grip strength was not the same used in the Fried et al. ${ }^{1}$ study, however it is important to highlight that the instrument used in this study has similar characteristics to the one used in the Fried et al. ${ }^{1}$ study and all the recommended criteria by the authors were followed, and finally the sample size that, even small, was sufficient to detect significant differences and relationships between variables.

The lack of studies limited the comparisons of the results presented in this study. On the other hand, it allowed an analysis based on reasonable possibilities that could be confirmed by future studies. Larger samples size and other methodological designs involving this population are necessary to investigate the relationship between frailty syndrome and respiratory function.

\section{Conclusions}

This study showed that the maximal respiratory pressures decreased according to the frailty condition among the non-frail, pre-frail and frail elderly. It was observed a positive correlation between inspiratory muscle strength, expiratory muscle strength and hand grip strength in pre-frail elderly and positive correlation between maximal expiratory pressure and physical activity level in the non-frail elderly. Further investigations with intervention or prevention programs, which incorporate actions to minimize the loss of respiratory function are important in order to reverse or prevent the progression of the frailty condition.

\section{Acknowledgments}

The Department of Higher Education of the Ministry of Education, the UBS Dona Conceição Aparecida Ferreira and the Municipal Secretariat of Uberaba, MG, Brazil.

\section{References}

1. Fried LP, Tangen CM, Walston J, Newman AB, Hirsch C, Gottdiener J, et al. Frailty in older adults: evidence for a phenotype. J Gerontol A Biol Sci Med Sci. 2001;56(3):M146-56. PMid:11253156. http://dx.doi. org/10.1093/gerona/56.3.M146 
2. Bandeen-roche K, Xue QL, Ferrucci L, Walston J, Guralnik JM, Chaves P, et al. Phenotype offrailty: characterization in the women's health and aging studies. J Gerontol A Biol Sci Med Sci. 2006;61(3):262-6. PMid:16567375

3. Rockwood K, Stadnyk K, MacKnight C, McDowell I, Hébert R, Hogan DB. A brief clinical instrument to classify frailty in elderly people. Lancet. 1999;353(9148):205-6. PMid:9923878.

4. Fried LP, Ferrucci L, Darer J, Williamson JD, Anderson G. Untangling the concepts of disability, frailty, and comorbidity: implications for improved targenting and care. J Gerontol A Biol Sci Med Sci. 2004;59(3):255-63. PMid:15031310.

5. Rockwood K, Hogan DB, MacKnigth C. Conceptualisation and measurement of frailty in elderly people. Drugs Aging. 2000;17(4):295-302. PMid:11087007.

6. Vaz Fragoso CA, Enright P, McAvay G, Van Ness PH, Gill TM. Frailty and respiratory impairment in older persons. Am J Med. 2012;125(1):79-86. PMid:22195532.

7. Janssens JP. Aging of the respiratory system: impact on pulmonary function tests and adaptation to exertion. Clin Chest Med. 2005;26(3):469-484. PMid:16140139.

8. Stanojevic S, Wade A, Stocks J, Hankinson J, Coates $\mathrm{AL}$, Pan $\mathrm{H}$, et al. Reference ranges for spirometry across all ages: a new approach. Am J Respir Crit Care Med. 2008;177(3):253-60. PMid:18006882.

9. Vaz Fragoso CA, Gill TM.Respiratory impairment and the aging lung: a novel paradigm for assessing pulmonary function. J Gerontol A Biol Sci Med Sci. 2012;67(3):264-75. PMid:22138206. http://dx.doi. org/10.1093/gerona/glr198

10. Summerhill EM, Angov N, Garber C, McCool FD. Respiratory muscle strength in the physically active elderly. Lung. 2007;185(6):315-20. Pmid:17917778. http://dx.doi.org/10.1007/s00408-007-9027-9

11. Doherty TJ. Invited review: aging and sarcopenia. J Appl Physiol. 2003;95(4):1717-27. PMid:12970377. http:// dx.doi.org/10.1152/japplphysiol.00347.2003

12. Cress ME, Meyer M. Maximal voluntary and functional performance levels needed for independence in adults aged 65 to 97 years. Phys Ther. 2003;83(1):37-48. PMid:12495411.

13. Vasconcellos JAC, Britto RR, Parreira VF, Cury AC, Ramiro SM. Pressões respiratórias máximas e capacidade funcional em idosas assintomáticas. Fisioter Mov. 2007;20(3):93-100.

14. Janssens JP, Pache JC, Nicod LP. Physiological changes in respiratory function associated with ageing. Eur Respir J. 1999;13(1):197-205. PMid:10836348. http://dx.doi. org/10.1034/j.1399-3003.1999.13a36.x

15. Britto RR, Vieira DSR, Rodrigues JM, Prado LF, Parreira VF. Comparação do padrão respiratório de adultos e idosos saudáveis. Rev Bras Fisioter. 2005;9(3):281-7.

16. Watsford ML, Murphy AJ, Pine MJ. The effects of ageing on respiratory muscle function and performance in older adults. J Sci Med Sport. 2007;10(1):36-44. PMid:16814604.

17. Freitas FS, Ibiapina CC, Alvim CG, Britto RR, Parreira VF. Relationship between cough strength and functional level in elderly. Rev Bras Fisioter. 2010;14(6):470-6. http:// dx.doi.org/10.1590/S1413-35552010000600004

18. Weiss CO, Hoenig HH, Varadhan R, Simonsick EM, Fried L. Relationships of cardiac, pulmonary, and muscle reserves and frailty to exercise capacity in older women. J Gerontol A Biol Sci Med Sci. 2010;65(3):287-94. PMid:19822621.

19. Brucki SMD, Nitrini R, Caramelli P, Bertolucci PHF, Okamoto IH. Sugestões para o uso do Mini-Exame do Estado Mental no Brasil. Arq Neuropsiquiatr. 2003;61(3B):777-81. http://dx.doi. org/10.1590/S0004-282X2003000500014

20. Silva, SLA, Silva VG, Máximo LS, Dias JMD, Dias RC. Comparação entre diferentes pontos de corte na classificação do perfil de fragilidade de idosos comunitários. Geriatr Gerontol. 2011;5(3):130-5.

21. Batistone SST, Neri AL, Cupertino APFB. Validade da escala de depressão do Center for Epidemiological Studies entre idosos brasileiros. Rev Saúde Pública. 2007;41(4):589-605.

22. Souza AC, Magalhães LC, Teixeira-Salmela LF. Adaptação transcultural e análise das propriedades psicométricas da versão brasileira do perfil de atividade humana. Cad Saúde Pública. 2006;22(12):2623-36. http://dx.doi.org/10.1590/ S0102-311X2006001200012

23. Sociedade Brasileira de Pneumologia e Tisiologia. Diretrizes para testes de função pulmonar. J Pneumol. 2002;28(Suppl 3):S1-238.

24. Pereira CAC, Sato T, Rodrigues SC. Novos valores de referência para espirometria forçada em brasileiros adultos de raça branca. J Bras Pneumol. 2007;33(4):397-406. http://dx.doi.org/10.1590/S1806-37132007000400008

25. Supinski G. Determination and interpretation of inspiratory and expiratorypressure measurements. Clin Pulm Med. 1999;6(2):118-25.

26. American Thoracic Society/European Respiratory Society:ATS/ERS Statement on respiratory muscle testing. Am J Respir Crit Care Med. 2002;166(4):518-624. PMid:12186831. http://dx.doi.org/10.1164/ rccm.166.4.518

27. Santana H, Zoico E, Turcato E, Tosoni P, Bissoli L, Olivieri M, et al. Relation between body composition, fat distribution, and lung function in elderly men. Am J Clin Nutr. 2001;73(4):827-31. PMid:11273860.

28. Pride NB. Ageing and changes in lung mechanics. Eur Respir J. 2005;26(4):563-565. http://dx.doi.org/10.1183 /09031936.05.00079805

29. Cook NR, Evans DA, Scherr PA, Speizer FE, Vedal $\mathrm{S}$, Branch LG, et al. Peak expiratory flow rate in an elderly population. Am J Epidemiol. 1989;130(1):66-78. PMid:2787111.

30. Meyer KC. Aging. Proc Am Thorac Soc. 2005;2(5):433-9. PMid:16322596.

31. Chaunchaiyakul R, Groeller H, Clarke JR, Taylor NAS. The impact of aging and habitual physical activity on static respiratory work at rest and during exercise. Am J PhysiolLung Cell Mol Physiol. 2004;287(6):1098106. PMid:15246978. http://dx.doi.org/10.1152/ ajplung.00399.2003 
32. Laghi F, Tobin MJ. State of the Art. Disorders of the respiratory muscles. Am J Respir Crit Care Med. 2003;168(1):10-48. http://dx.doi.org/10.1164/ rccm. 2206020

33. Polla B, D'Antona G, Bottinelli R, Reggiani C. Respiratory muscle fibres: specialisation and plasticity. Thorax. 2004;59(9):808-17. PMCid:PMC1747126. http:// dx.doi.org/10.1136/thx.2003.009894

34. Kim J, Sapienza CM. Implications of expiratory muscle strengthtraining for rehabilitation of the elderly: Tutorial. J RehabilRes Dev. 2005;42(2):211-24. PMid:15944886. http://dx.doi.org/10.1682/JRRD.2004.07.0077

35. Tolep K, Higgins N, Muza S, Griner G, Kelsen SG. Comparison of diaphragm strength between healthy adult elderly and young men. Am J Respir Crit Care Med. 1995;152(2):677-82. PMid:7633725.

36. Polkey MI, Hamnegård CH, Hughes PD, Rafferty GF, Green M, Moxham J. Influence of acute lung volume change on contractile properties of human diaphragm. J Appl Physiol. 1998;85(4):1322-8. PMid:9760323.

37. Hardie JA, Vollmer WM, Buist AS, Ellingsen I, Mørkve O. Reference values for arterial blood gases in the elderly. Chest. 2004;125(6):2053-60. PMid:15189921.

38. Kim MJ. Respiratory muscle training: implications for patient care. Heart Lung. 1984;13(4):333-40. PMid:6564100.

39. Abbrecht PH, Rajagopal KR, Kyle RR. Expiratory muscle recruitment during inspiratory flow-resistive loading and exercise. Am Rev Respir Dis. 1991;144(1):113-20. PMid:2064116.

40. Nomori H, Kobayashi R, Fuyuno G, Morinaga S, Yashima H. Preoperative respiratory muscle training. Assessment in thoracic surgery patients with special reference to postoperative pulmonary complications. Chest. 1994;105(6):1782-8. PMid:8205877

41. Olgiati R, Girr A, Hügi L, Haegi V. Respiratory muscle training in multiple sclerosis: a pilot study. Schweiz Arch Neurol Psychiatr. 1989;140(1):46-50. PMid:2467371

42. Dias CM, Pássaro CP, Cagido VR, Einicker-Lamas M, Lowe J, Negri EM, et al. Effects of undernutrition on respiratory mechanics and lung parenchyma remodeling. J Appl Physiol. 2004;97(5):1888-96. PMid:15194671,doi: 10.1152/japplphysiol.00091.2004.

43. Moreira D, Alvarez RRA, Gogoy JR, Cambraia AN.Abordagem sobre preensão palmar utilizando o dinamômetro JAMAR ${ }^{\circledR}$ : umarevisão de literatura. Rev Bras Ciên Mov. 2003;11(2):95-9.

44. Sayers SP, Guralnik JM, Thombs LA, Fielding RA. Effect of leg muscle contraction velocity on functionalperformance in older men and women. J Am GeriatrSoc. 2005;53(3):467-71. PMid:15743291. http:// dx.doi.org/10.1111/j.1532-5415.2005.53166.x

45. Rolland Y, Lauwers-Cances V, Cesari M, Vellas B, Pahor M, Grandjean H. Physical performance measures as predictors of mortalityin a cohort of community-dwelling older French women. Eur J Epidemiol. 2006;21(2):113-22. PMid:16518679. http:// dx.doi.org/10.1007/s10654-005-5458-X

46. Lang T, Streeper T, Cawthon P, Baldwin K, Taaffe DR, Harris TB. Sarcopenia: etiology, clinical consequences, intervention, andassessment. Osteoporosis Int. 2010;21(4):543-59. PMCID:PMC2832869. http:// dx.doi.org/10.1007/s00198-009-1059-y

47. Walston J, Hadley EC, Ferrucci L, Guralnik JM, Newman AB, Studenski SA, et al. Research agenda for frailty in older adults: toward a better understanding of physiology and etiology: summary from the American Geriatrics Society/ National Institute on Aging Research Conference on Frailty in Older Adults. J Am Geriatr Soc. 2006;54(6):991-1001. PMid:16776798.

48. Graf A, Judge JO, Ounpuu S, Thelen DG. The effect of walkingspeed on lower-extremity joint powers among elderly adults who exhibitlow physical performance. Arch Phys Med Rehabil. 2005;86(11):2177-83. PMid:16271567. http://dx.doi.org/10.1016/j.apmr.2005.06.007

\section{Correspondence}

Maycon Sousa Pegorari

Rua Ilídio Renato Costa Cruvinel, 095, Bairro Boa Vista

CEP 38071-220, Uberaba, MG, Brasil

e-mail: mayconpegorari@yahoo.com.br 